\title{
Fatty Acid Ethyl Esters from Animal Fat Using Supercritical Ethanol Process
}

\author{
David Bolonio, ${ }^{\dagger}$ Philipp Marco Neu, ${ }^{\ddagger}$ Sigurd Schober, ${ }^{\ddagger}$ María-Jesús García-Martínez, ${ }^{\dagger}$ Martin Mittelbach, ${ }^{\ddagger}$ \\ and Laureano Canoira*t; \\ ${ }^{\dagger}$ Department of Energy \& Fuels, ETS Ingenieros de Minas y Energía, Universidad Politécnica de Madrid, Ríos Rosas 21, 28003 \\ Madrid, Spain \\ ${ }^{\ddagger}$ Institute of Chemistry, NAWI Graz, University of Graz, Heinrichstraße 28, 8010 Graz, Austria
}

Supporting Information

\begin{abstract}
Biodiesel is currently produced from a catalytic transesterification reaction of edible and nonedible oils with methanol. New policies are encouraging the development of advanced biofuels produced from lignocellulosic feedstocks or industrial waste as animal fat. This material is less expensive than current oils but usually has high content of free fatty acids and a pre-esterification reaction becomes necessary, increasing the cost of the catalytic process. The production of biodiesel using supercritical alcohols is appropriate for materials with high acidity and water content; therefore, the use of this method for animal fat is a promising alternative. Two different processes have been studied: a single-step direct transesterification using supercritical ethanol and a two-step process of hydrolysis and esterification. Ethanol, instead of methanol, has been used as the reagent because it can be produced from biomass via fermentation, resulting in a complete renewable biofuel. The final conversion and degradation of unsaturated fatty acid esters, which is the main drawback of these high temperature and pressure processes, have been studied through the change of several parameters such as temperature, ethanol:animal fat molar ratio, and reaction time.
\end{abstract}

\section{INTRODUCTION}

World energy production was 13.800 Mtoe in 2014, fossil fuels accounting for $81.2 \%$. Among nonfossil sources, biofuels and fuels from waste maintained their share of $10.2 \%{ }^{1}$ Industry remained the largest consuming sector and was followed by the transport sector, which accounted for $28 \%$, and biofuels provided $4 \%$ of the total world road transport fuel. In order to reduce the dependency of fossil fuels and diminish overall $\mathrm{CO}_{2}$ emissions, many countries have proposed to increase the share of biofuels in the next few years, as a target average of $10 \%$ of share in the transport fuel in $2020 .^{2}$ To make this possible and continue the increasing use of biofuels, the research community has encouraged the advanced biofuels, which (1) are produced from lignocellulosic feedstocks (i.e., agricultural and forestry residues or wood based biomass), nonfood crops, or industrial waste and residue streams; (2) have low $\mathrm{CO}_{2}$ emission or high greenhouse gas (GHG) emissions reduction potential; and (3) have zero or low indirect land use change (ILUC) impact.

In this regard, animal fat is an attractive feedstock for the production of biofuel, specifically biodiesel. It is obtained through a process of rendering, which converts animal byproducts into stable and value-added materials. These animal byproducts arise from slaughterhouse, meat, and dairy processing industry as well as from food retail trade, restaurants, and industrial kitchens.

Some of the advantages of using animal fat for the production of biodiesel are the following: (1) Much of the animal fat produced is not considered edible and, although used for some industrial purposes, its market is very limited, what makes it a byproduct with lower costs than vegetable oils. (2) It is produced in large amounts by food processing and service facilities spread all over the world. (3) A life cycle analysis (LCA) of the production of biodiesel from animal fat conducted by the Institute for Product Development at the Technical University of Denmark ${ }^{3}$ resulted in a net overall reduction in GHG emissions and came out as the most preferable transport biofuel in comparison to rapeseed biodiesel and maize kernels bioethanol. Concerning the properties of biodiesel obtained from animal fat, several studies ${ }^{4,5}$ have reported higher cetane numbers $(\mathrm{CNs})$ than vegetable oil biodiesel fuels (values over 60 are common, while, for example, soybean oil based biodiesel usually has a $\mathrm{CN}$ of about 48-52). In addition, the saturated fatty acids in animal fats contribute to better oxidative stability in contrast with vegetable oils which contain higher amounts of polyunsaturated fatty acids, such as linoleic and linolenic acid, that makes them prone to rancidity. The major drawback resides in the higher cloud (CP) and pour points (PP) which would make necessary the implementation of techniques to improve the cold flow performance such as PP depressants $^{6}$ or winterization. ${ }^{7}$

Animal fats include tallow (beef tallow from domestic cattle and mutton tallow from sheep), pork lard (rendered pork fat), and chicken fat. All of them are high in free fatty acids (FFAs) content and therefore need a more expensive processing method for their conversion to biodiesel. This is the main drawback for the generalized use of biodiesel from animal fat and can be overcome following different strategies. Bhatti et al. ${ }^{8}$ studied the acid-catalyzed transesterification of waste tallow reporting the optimal processing conditions for $5 \mathrm{~g}$ of mutton

Received: October 5, 2017

Revised: December 13, 2017

Published: December 14, 2017 
tallow: $2.5 \mathrm{~g}$ of concentrated $\mathrm{H}_{2} \mathrm{SO}_{4}$ and molar rate oil/ methanol $1: 30$ at $60{ }^{\circ} \mathrm{C}$, yielding $93.21 \%$ of biodiesel after $24 \mathrm{~h}$. Meanwhile, Dias et al. ${ }^{9}$ pretreated acid waste lard with an acid

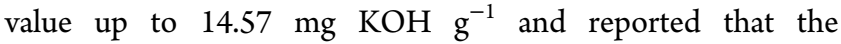
pretreatment was effective, enabling acid waste lard to serve as a single raw material for biodiesel production with acceptable quality, but a low yield (65 wt \%). As an alternative, Lu et al. ${ }^{10}$ applied the use of Candida $s p$. 99-125 to enzymatically transesterified lard obtaining as optimal conditions for $1 \mathrm{~g}$ of lard: $8 \mathrm{~mL}$ of $n$-hexane as solvent, $0.2 \mathrm{~g}$ of immobilized lipase, $20 \%$ of water at a temperature of $40{ }^{\circ} \mathrm{C}$, and a three-step addition of methanol $(30 \mathrm{~h})$; final yield of fatty acid methyl esters (FAMEs) was 87.4\%. In addition, Alptekin et al. ${ }^{11}$ found as optimum conditions to transform chicken fat with $13.45 \%$ of FFAs the following: 20\% sulfuric acid and 40:1 methanol molar ratio for $80 \mathrm{~min}$ at $60{ }^{\circ} \mathrm{C}$; the methyl ester yield was $87.4 \%$. Best results are obtained by enzymatic and acid-catalyzed transesterification, but both reactions are slower and have lower yields than the alkaline-catalyzed transesterification. Moreover, enzymatic transesterification has still important costs while acid-catalyzed transesterification needs a higher molar ratio of alcohol to oil, is strongly inhibited by the presence of water, and causes corrosion problems and environmental threat. ${ }^{12}$

As an alternative to the methods described above, the supercritical fluids transesterification has been considered recently as a noncatalyst method with several notable advantages over the conventional processes. ${ }^{13}$ For reactions in supercritical methanol and ethanol, no catalyst is required and nearly complete conversions can be achieved in a very short time, primarily because supercritical alcohol and oil coexist in a single phase. The process becomes especially interesting when dealing with high FFAs feedstocks as waste cooking oil ${ }^{14}$ or algae, ${ }^{15}$ saving the cost of the required acid preesterification reaction. There are two distinguished supercritical processes: (1) A single-step transesterification, which happens at drastic reaction conditions, $350{ }^{\circ} \mathrm{C}$ and $20-50 \mathrm{MPa} ;{ }^{16-18}$ and (2) a two-step process consisting in a hydrolysis of triacylglycerides to FFAs in subcritical water and subsequent methyl or ethyl esterification of FFAs to fatty acid methyl (FAME) or ethyl (FAEE) esters without any catalyst. ${ }^{19,20}$ The two-step process happens at more moderate reaction conditions $\left(270{ }^{\circ} \mathrm{C} / 7-20 \mathrm{MPa}\right)$ than those of the one-step process. Furthermore, reaction of glycerol with final esters can be suppressed because glycerol is removed away prior to esterification, improving the quality of the biodiesel produced.

A worrying problem of supercritical reactions for biodiesel production is the degradation of unsaturated compounds, ${ }^{21,22}$ which can produce undesirable products and a reduction of yield. It has been reported that side reactions of unsaturated FAMEs occur when the reaction temperature is over $300{ }^{\circ} \mathrm{C}$ and can lead to a significant loss of material. ${ }^{23}$

Animal fat seems an ideal feedstock to apply the described techniques, because of its high FFA and the low polyunsaturated composition, which prevents lost by degradation. This work studies the production of biodiesel from animal fat (tallow) with supercritical ethanol, comparing the direct transesterification and the two-step process of hydrolysis and esterification. Yields and degradation of polyunsaturated compounds have been assessed with changes of the temperature, ethanol:animal fat molar ratio, and reaction time.

\section{MATERIALS AND METHODS}

2.1. Characterization of the Animal Fat. Tallow feedstock was provided by Argent Energy (U.K.) Limited, whose properties are shown in Table 1. Density and viscosity were measured following the

Table 1. Animal Fat Properties

\begin{tabular}{llc}
\multicolumn{1}{c}{ properties } & animal fat & standard deviation \\
density $\left(\mathrm{g} \cdot \mathrm{cm}^{-3}\right)$ & 0.897 & \pm 0.0002 \\
dynamic viscosity $(\mathrm{mPa} \cdot \mathrm{s})$ & 39.1 & \pm 0.04 \\
kinematic viscosity $\left(\mathrm{mm}^{2} \cdot \mathrm{s}^{-1}\right)$ & 43.6 & \pm 0.04 \\
water content $(\mathrm{ppm})$ & 314.6 & \pm 5.89 \\
FFAs content $\left(\mathrm{mg} \mathrm{KOH} \cdot \mathrm{g}^{-1}\right)$ & 20.8 & \pm 0.02 \\
total fatty acids $(\mathrm{wt} \%)$ & 92.9 & \\
S $(\mathrm{ppm})$ & 25 & \pm 1.93 \\
$\mathrm{Na}(\mathrm{ppm})$ & 102 & \pm 2.23 \\
$\mathrm{~K}(\mathrm{ppm})$ & 41 & \pm 1.01 \\
$\mathrm{Ca}(\mathrm{ppm})$ & 171 & \pm 4.20 \\
$\mathrm{Mg}(\mathrm{ppm})$ & 22.7 & \pm 0.79 \\
$\mathrm{P}(\mathrm{ppm})$ & 182 & \pm 0.60 \\
\hline
\end{tabular}

standard analytical procedures EN ISO $3675^{24}$ and EN ISO 3104, ${ }^{25}$ respectively, using the Anton Paar (AUT) SVM 3000 Stabinger Viscometer. Water content was determined through a coulometric Karl Fischer titration according to the EN ISO $12937 .{ }^{26}$ FFAs were measured according to the standard EN $14104{ }^{27}$ The analysis of the total fatty acid content was analyzed according to DGF-C-III $2 .{ }^{28}$ The sulfur content was investigated by ultraviolet fluorescence spectrometry using a Mitsubishi TS-100 total sulfur analyzer equipped with a sulfur detector SD-100 according to EN ISO 20846. ${ }^{29}$ Sodium (Na), potassium $(\mathrm{K})$, calcium $(\mathrm{Ca})$, magnesium $(\mathrm{Mg})$, and phosphorus $(\mathrm{P})$ were determined by inductively coupled plasma optical emission spectrometry (Spectro Genesis ICP-OES) based on EN $14538^{30}$ and EN $14107 .^{3}$

2.2. Catalyzed Biodiesel Production. FAEEs produced by nonsupercritical ethanol were used as a control method and prepared following an adaption of a previously reported protocol. ${ }^{5}$ The animal fat was heated to $95{ }^{\circ} \mathrm{C}$ with stirring at $500 \mathrm{rpm}$, and 85 wt \% orthophosphoric acid ( $0.2 \mathrm{vol} \%$ of the fat) was added to the reactor, holding the reaction for $30 \mathrm{~min}$. Then, the reaction mixture was centrifuged at $3000 \mathrm{rpm}$ for $15 \mathrm{~min}$, and the bottom part in the centrifuge tubes (phosphoglycerides or gums) was removed. The esterification reaction with absolute ethanol in excess (molar ratio of ethanol:animal fat, 6:1) was catalyzed by $p$-toluenesulfonic acid (mass ratio animal fat: $p$-toluensulfonic acid, 200:1). The reaction was heated to $70{ }^{\circ} \mathrm{C}$ with stirring at $600 \mathrm{rpm}$ for $4 \mathrm{~h}$. At the end of the reaction, acid catalyst was neutralized and water removed by freshly calcined calcium oxide, produced from calcium carbonate heated at $850{ }^{\circ} \mathrm{C}$ overnight (mass ratio animal fat:calcium oxide, 50:1), added to the reactor at $70{ }^{\circ} \mathrm{C}$ with stirring. Both calcium hydroxide and $p$ toluenesulfonate were removed by centrifugation. The resultant mixture of FAEEs, animal fat, and ethanol was used for the transesterification step without any further treatment, only with adjustment of the amount of ethanol. The mixture was heated to 70 ${ }^{\circ} \mathrm{C}$ with stirring at $600 \mathrm{rpm}$. Sodium ethoxide (mass ratio animal fat:sodium ethoxide, 100:2) dissolved in ethanol (molar ratio of ethanol:animal fat, 6:1) was added to the reaction mixture. After $3 \mathrm{~h}$, the reaction mixture was cooled to room temperature and centrifuged at $3000 \mathrm{rpm}$ for $5 \mathrm{~min}$, separating the upper biodiesel phase from the lower glycerol phase. The biodiesel was transferred to a rotary evaporator to eliminate the excess ethanol. For purification, the catalyst was neutralized with $25 \mathrm{vol} \%$ of a $1 \mathrm{wt} \%$ solution of citric acid in a decantation funnel, and separated from the aqueous layer by centrifugation at $3000 \mathrm{rpm}$ for $5 \mathrm{~min}$. The biodiesel was washed with $100 \mathrm{vol} \%$ of a $3 \mathrm{wt} \%$ solution of sodium chloride, and later with three batches of 100 vol \% of deionized water and separated by centrifugation at $3000 \mathrm{rpm}$ for $5 \mathrm{~min}$. Finally, it was dried by stirring with 8 wt \% of $4 \AA$ molecular sieves, previously dried at $200{ }^{\circ} \mathrm{C}$ for $2 \mathrm{~h}$, 
and filtered through a $0.45 \mu \mathrm{m}$ filter. Final composition was assessed by gas chromatography-mass spectrometry (GC-MS) to identify the different compounds and gas chromatography-flame ionization detector (GC-FID) to quantify the percentage of esters in the mixture (shown in Figure 1).

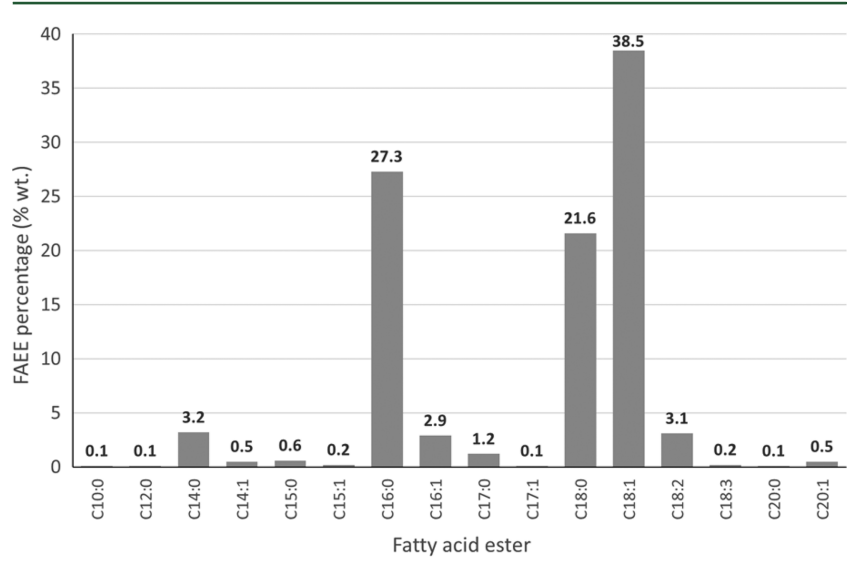

Figure 1. FAEE profile (wt \%) of the animal fat. Total fatty acid ester content 99.7 wt \%.

2.3. Supercritical Methods. 2.3.1. One-Step Process. Animal fat and ethanol were mixed at different ratios to react without any catalyst at temperatures and periods of time specified in the Results and Discussion section. All the reactions happened with $300 \mathrm{~mL}$ initial volume of reactants in a $0.5 \mathrm{~L}$ high pressure vessel (Parr Instrument Company, Moline, IL USA). Temperature was precisely controlled and pressure measured by the $4848 \mathrm{~B}$ Expanded Reactor Controller. Afterward, the reaction mixture was cooled to room temperature with a water cooling system and centrifuged at $3000 \mathrm{rpm}$ for $5 \mathrm{~min}$, separating the biodiesel from the lower glycerol phase. The biodiesel was transferred to a rotary evaporator to eliminate the excess ethanol, and the efficiency of the reaction was assessed through gel permeation chromatography (GPC) (to assess the percentage of nonreacted triacylglycerides) and titration with $0.1 \mathrm{M}$ potassium hydroxide (to assess the percentage of FFAs). ${ }^{27}$ The remaining FFAs were esterified at $78{ }^{\circ} \mathrm{C}$ for $4 \mathrm{~h}$ using a commercial acidic polymer-based resin (Lewatit GF 101) and ethanol in a molar ratio ethanol-FFAs, 6:1. Finally, the reaction mixture was filtered through a $0.45 \mu \mathrm{m}$ filter, and the ethanol was removed by a rotary evaporator. Final composition was assessed by GC-MS and GC-FID.

2.3.2. Two-Step Process. Animal fat and water were reacted without any catalyst for $1 \mathrm{~h}$ at temperatures specified in the Results and Discussion section and in the same high pressure reactor described previously, using a molar ratio water:animal fat 2:1 and a total initial volume of $300 \mathrm{~mL}$ of reactants. Afterward, the reaction mixture was cooled in a decantation funnel, where $100 \mathrm{vol} \%$ of hexane was added to dissolve the FFAs and improve their separation with the glycerol and water. The FFAs solution was transferred to a rotary evaporator to eliminate the hexane, and a sample was taken to measure the efficiency of the hydrolysis through GPC.

Esterification of FFAs was carried out in the high pressure reactor, at a molar ratio ethanol:FFAs 7:1, temperature and periods of time specified in the Results and Discussion section. The biodiesel was transferred to a rotary evaporator to eliminate the excess ethanol, and the efficiency of the reaction was determined through GPC and titration with $0.1 \mathrm{M}$ potassium hydroxide. After removal of the excess ethanol, residual FFAs were turned into esters using Lewatit GF 101 beads as described previously. Finally, the reaction mixture was filtered through a $0.45 \mu \mathrm{m}$ filter and the ethanol was removed by a rotary evaporator. Final composition was assessed by GC-MS and GC-FID.

2.4. Gel Permeation Chromatography (GPC). GPC has already been proved to be a useful technique to study transesterification reactions. $^{32,33}$ A Hewlett-Packard (HP) 1100 Series GPC analysis system coupled to the refractive index (RI) detector Knauer K-2301 was used for the analysis. Two consecutive Phenomenex Phenogel 5 $\mu \mathrm{m}$ size exclusion columns composed of highly cross-linked polystyrene-divinylbenzene (PSDVB) were used for separation (pore size 100 and $500 \AA$ ). The diameter and length of the tubes were 7.8 and $300 \mathrm{~mm}$, respectively. The following analytical conditions were used: injection volume: $50 \mu \mathrm{L}$; temperature: $40{ }^{\circ} \mathrm{C}$; solvent: tetrahydrofuran (THF); flow rate: $1 \mathrm{~mL} \cdot \mathrm{min}^{-1}$. The amounts of tri-, di-, and monoglycerides, separated from the FFAs and ethyl esters were analyzed by the HP interface 35900 (see the Supporting Information for examples of GPC chromatograms).

2.5. Gas Chromatography. 2.5.1. Gas Chromatography-Mass Spectrometry (GC-MS). An HP 6890 series II gas chromatograph equipped with a 5973 mass selective detector and a split/splitless injector was used for the analysis. A J\&W 122-5532UI column $(30 \mathrm{~m}$ $\times 0.25 \mathrm{~mm}$ i.d. $\times 0.25 \mu \mathrm{m})$ was used for separation. The following analytical conditions were used: injector model, Agilent 6805 Series model; injection volume: $1 \mu \mathrm{L}$; injection temperature: $250{ }^{\circ} \mathrm{C}$; split ratio: 50:1; column flow $(\mathrm{He}): 1 \mathrm{~mL} \cdot \mathrm{min}^{-1}$ constant flow mode; oven program: $50{ }^{\circ} \mathrm{C}$, held for $9 \mathrm{~min}$, to $310^{\circ} \mathrm{C}$ at $10^{\circ} \mathrm{C} \cdot \mathrm{min}^{-1}$, held for 10 min. Mass spectra of electron ionization: $70 \mathrm{eV} ; \mathrm{m} / z$ scan from 50 to $800 \mathrm{Da}$ by quadrupole detector set at $150{ }^{\circ} \mathrm{C}$; resolution: 1000; source temperature: $230{ }^{\circ} \mathrm{C}$. Chemical compounds were identified using the software MSD ChemStation E.02.02.1431 Data Analysis Application of Agilent and the spectral library Wiley 275.

2.5.2. Gas Chromatography-Flame Ionization Detector (GCFID). An Agilent 7890 GC System equipped with a FID detector and split/splitless injector was used for the analysis. An HP-InnoWax column $(30 \mathrm{~m} \times 0.32 \mathrm{~mm}$ i.d. $\times 0.25 \mu \mathrm{m})$ of cross-linked polyethylene glycol was used for the separation. The following analytical conditions, based on the EN 14103:2011 protocol ${ }^{34}$ were used for the analysis: injector temperature: $210^{\circ} \mathrm{C}$; split ratio: 80:1; injection volume: $1 \mu \mathrm{L}$; column flow (He): $2 \mathrm{~mL} \cdot \mathrm{min}^{-1}$ constant flow mode; FID temperature: $250{ }^{\circ} \mathrm{C} ; \mathrm{H}_{2}$ flow: $30 \mathrm{~mL} \cdot \mathrm{min}^{-1}$; airflow: $350 \mathrm{~mL} \cdot \mathrm{min}^{-1}$; oven program: $60{ }^{\circ} \mathrm{C}$ held for $2 \mathrm{~min}$, to $200{ }^{\circ} \mathrm{C}$ at $10^{\circ} \mathrm{C} \cdot \mathrm{min}^{-1}$, to $240{ }^{\circ} \mathrm{C}$ at $5{ }^{\circ} \mathrm{C}$. $\mathrm{min}^{-1}$, held for $7 \mathrm{~min}$; sample preparation: $250 \mathrm{mg}$ of sample in a 10 $\mathrm{mL}$ vial with a $5 \mathrm{~mL}$ solution of ethyl nonadecanoate in hexane $(10$ $\left.\mathrm{mg} \cdot \mathrm{mL}^{-1}\right)$.

Table 2. Yields of One-Step Process Experiments with Different Ethanol Concentration, Temperature, Time Duration, or Ethanol:Animal Fat Molar Ratio

\begin{tabular}{|c|c|c|c|c|c|c|c|c|c|c|}
\hline & ${ }^{a}$ OSR1 & OSR2 & OSR3 & OSR4 & OSR5 & OSR6 & OSR7 & OSR8 & OSR9 & OSR10 \\
\hline type of ethanol & $96 \%$ & $96 \%$ & $96 \%$ & $96 \%$ & $96 \%$ & absolute & absolute & absolute & absolute & absolute \\
\hline${ }^{b}$ temperature $\left({ }^{\circ} \mathrm{C}\right)$ & 300 & 300 & 350 & 350 & 350 & 300 & 350 & 350 & 350 & 350 \\
\hline time $(\mathrm{min})$ & 40 & 120 & 40 & 40 & 120 & 40 & 40 & 40 & 120 & 120 \\
\hline molar ratio (ethanol:animal fat) & $40: 1$ & $40: 1$ & $20: 1$ & $40: 1$ & $20: 1$ & $40: 1$ & $20: 1$ & $40: 1$ & $20: 1$ & $40: 1$ \\
\hline$c_{\%}$ of FAEEs & 63.7 & 69.4 & 87.7 & 89.6 & 86.8 & 77.3 & 91.6 & 98.4 & 93.4 & 96.5 \\
\hline$c_{\%}$ of FFAs & 14.0 & 9.5 & 7.9 & 7.3 & 8.8 & 4.8 & 4.0 & 1.6 & 5.5 & 3.5 \\
\hline
\end{tabular}

${ }^{a}$ OSR: One-Step process Reaction. ${ }^{b}$ Temperature standard deviation: $\pm 0.2{ }^{\circ} \mathrm{C} .{ }^{c}$ Relative Standard Deviation (RSD) for percentages of FAEEs or FFAs was equal to or less than $2 \%$. 


\section{RESULTS AND DISCUSSION}

3.1. Reactions Yield. 3.1.1. One-Step Process. The conditions and results of the one-step process reactions (OSR) are shown in Table 2. Yield of FAEEs and percentage of remaining FFAs depend on the ethanol concentration, temperature, time, and ethanol:animal fat molar ratio of the experiments.

Effect of Ethanol Concentration. Production of anhydrous or absolute ethanol in large scale is commercially made by extractive distillation using conventional solvents, which consumes $50-80 \%$ of the energy used in a typical fermentation ethanol manufacturing. ${ }^{35}$ The use of $96 \%$ ethanol in the production of FAEEs could reduce the overall cost of the process. The comparison of the pairs of experiments OSR3OSR7, OSR4-OSR8, and OSR5-OSR9 shows how the use of absolute ethanol increases the yield of esters up to $98 \%$ and reduces the FFAs to less than 2\%. Previous experiments have shown that the presence of water did not have a significant effect on the yield studies, ${ }^{36}$ but these experiments were carried out in a $5 \mathrm{~mL}$ reaction vessel for 1-4 min. These very short reaction times mean that the samples have been heated and cooled almost instantly, not allowing the chemical equilibrium between FAEEs, FFAs, and water to be reached. The batch system of this work, with a $300 \mathrm{~mL}$ reactor, represents better real operation conditions, where the water affects the reaction yields. A possible solution to this problem is the use of a continuous process where the reaction temperature could be easily reached and the residence time reduced. ${ }^{37,38}$

Effect of the Temperature. Temperature is the most important factor for the noncatalyzed transesterification reaction. The pairs of experiments OSR1-OSR4 and OSR6OSR 8 show the yield of esters is reduced by more than $20 \%$ when the temperature goes from 350 to $300{ }^{\circ} \mathrm{C}$. This is consistent with other studies that show how only temperatures higher than $300{ }^{\circ} \mathrm{C}$ are useful for this process. ${ }^{39}$

Effect of the Residence Time. The dependence of the transesterification reaction on the residence time can be assessed comparing the pairs of experiments OSR1-OSR2, OSR3-OSR5, OSR7-OSR9, and OSR8-OSR10. When the residence time increases, the yield of FAEEs follows two different behaviors. On one hand, with lower temperature (300 ${ }^{\circ} \mathrm{C}$ for OSR1-OSR2), the yield of the reaction is low, and an increase in the residence time slightly improves it. On the other hand, when the temperature is $350{ }^{\circ} \mathrm{C}$ and the FAEE yield is high (near $90 \%$ or more), an increase in time diminishes the yield and increases the final percentage of FFAs. It seems that the presence of water produces an equilibrium between FAEEs and FFAs, which can increase the percentage of FFAs with time. There is also the possibility of side reactions of unsaturated FAEEs which can reduce their yield as it has been proposed by other studies ${ }^{21,23}$ and will be discussed in the last section of the results.

Effect of the Ethanol:Animal Fat Molar Ratio. The comparison of the pairs of reactions OSR3-OSR4, OSR7OSR8, and OSR9-OSR10 show that the yield of FAEEs increases significantly and the final FFAs decreases when the ethanol:animal fat ratio changes from 20:1 to 40:1. These results are consistent with other studies that point out the need of high methanol or ethanol ratios to optimize the transesterification yield ${ }^{40,41}$

3.1.2. Two-Step Process. The results of the hydrolysis reactions are summarized in Figure 2 and are consistent with

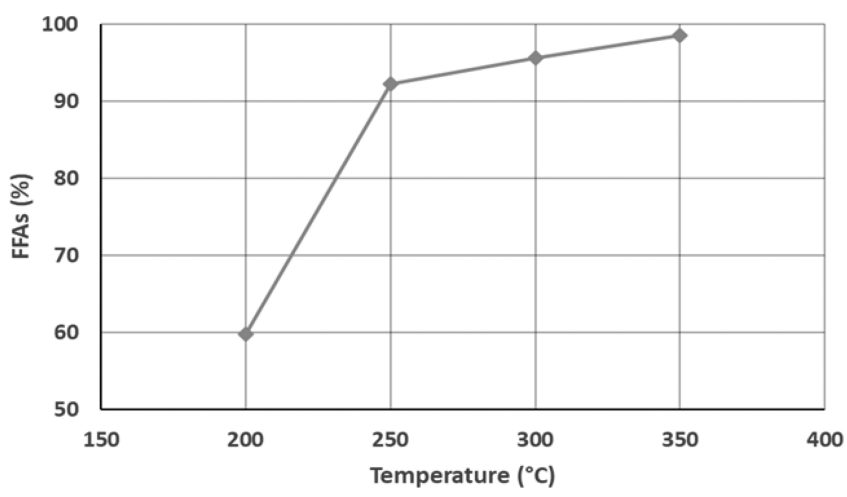

Figure 2. Yield of FFAs after hydrolysis of the animal fat with water (volume ratio water:animal fat, $2: 1$; residence time: $60 \mathrm{~min}$ ). RSD $\leq$ $2 \%$.

other studies. $^{19,42}$ The yield of FFAs reaches $90 \%$ or higher only when temperatures are $250{ }^{\circ} \mathrm{C}$ or higher. Moreover, another test was done to reduce the water from the volume ratio $2: 1$ to $1: 1$ (at $300{ }^{\circ} \mathrm{C}$ and $1 \mathrm{~h}$ of residence time), and the yield was reduced from $95.6 \%$ to $92.8 \%$. This confirms the need of big amounts of water to reach the optimum yield of the reaction. $^{19}$

The results of the esterification reactions are summarized in Figure 3. In the same way as in the hydrolysis process,

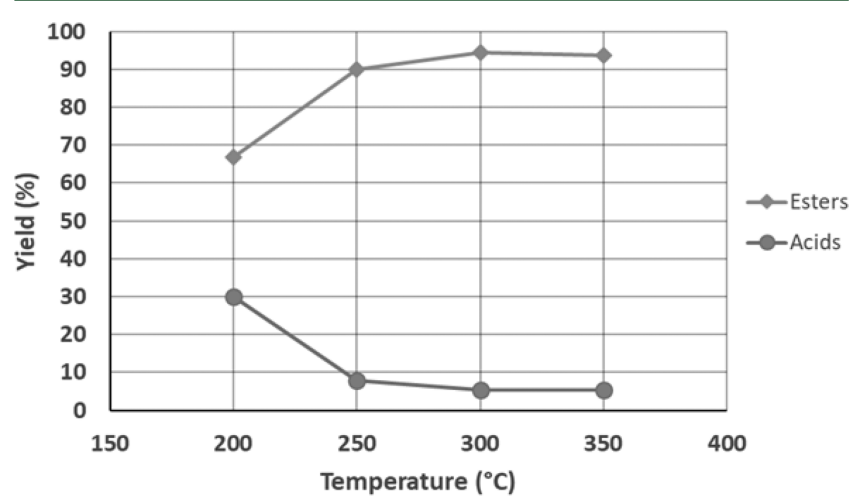

Figure 3. Yield of FAEEs after esterification of FFAs (molar ratio ethanol:FFAs, 7:1; residence time: $60 \mathrm{~min}$ ). RSD $\leq 2 \%$.

temperatures below $250{ }^{\circ} \mathrm{C}$ do not produce an optimum yield. It is worth noting that, as other studies have shown, ${ }^{43}$ optimum results are reached with a much lower ethanol:FFAs molar ratio (7:1) compared to the one used during the one-step process (40:1).

On the basis of these results, temperatures between 250 and $300{ }^{\circ} \mathrm{C}$ would reach a good yield both in hydrolysis and esterification reactions, while, in the case of one-step process reactions, the optimal temperature is $350{ }^{\circ} \mathrm{C}$. This difference of almost $100{ }^{\circ} \mathrm{C}$ has important consequences, economically because of the energy saving in heating but especially in the reduction of the polyunsaturated compounds degradation.

3.2. Degradation of Mono- and Polyunsaturated Compounds. 3.2.1. One-Step Process. Experiments with FAEEs yields higher than $90 \%$ and performed with absolute ethanol (low FFAs) were used for this study (see Figures 4 and 5 ). The percentages of oleic acid ethyl ester (C18:1) and linoleic acid ethyl ester (C18:2) obtained after the catalyzed method (section 2.2) were used as control. Figures 4 and 5 show how the degradation increases with higher residence time 


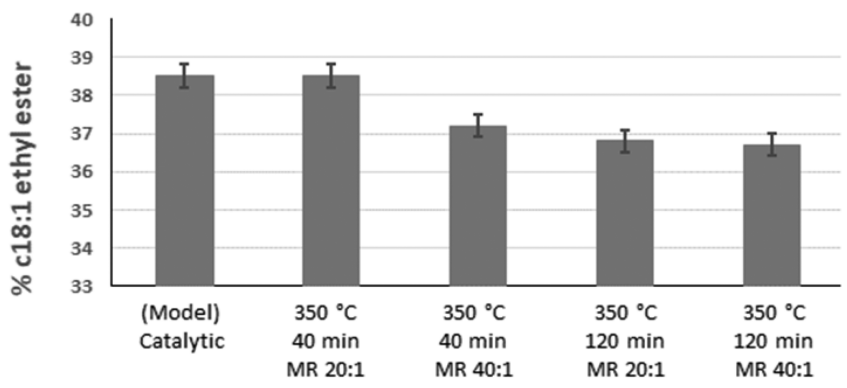

Figure 4. Percentage of oleic acid ethyl ester after one-step process reactions. MR: molar ratio.

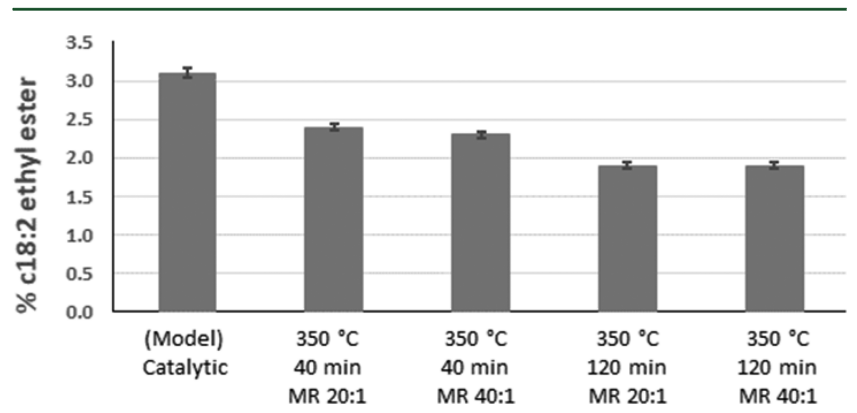

Figure 5. Percentage of linoleic acid ethyl ester after one-step process reactions.

or molar ratios. The increase in residence time causes a greater probability for side reactions to happen, while the increase in molar ratio causes an increase in pressure and accelerates the degradation.

The percentage of degradation of C18:1 and C18:2 ethyl esters was calculated according to eqs 1 and 2, where the subscript "model" refers to the concentrations obtained in the catalyzed method:

$\%$ degradation of $\mathrm{C} 18: 1$

$$
=\frac{[\mathrm{C} 18: 1]_{\text {model }}-[\mathrm{C} 18: 1]_{\text {experiment }}}{[\mathrm{C} 18: 1]_{\text {model }}} \times 100
$$

$\%$ degradation of $\mathrm{C} 18: 2$

$$
=\frac{[\mathrm{C} 18: 2]_{\text {model }}-[\mathrm{C} 18: 2]_{\text {experiment }}}{[\mathrm{C} 18: 2]_{\text {model }}} \times 100
$$

In the worst case $\left(350{ }^{\circ} \mathrm{C}, 120 \mathrm{~min}\right.$, and molar ratio ethanol:animal fat 40:1), the degradation of C18:1 ethyl ester reaches $4.7 \%$ (from $38.5 \%$ to $36.7 \%$ ) and of C18:2 ethyl ester reaches $38.7 \%$ (from $3.1 \%$ to $1.9 \%$ ). Meanwhile, using the following reaction conditions, $350{ }^{\circ} \mathrm{C}, 40 \mathrm{~min}$, and molar ratio ethanol:animal fat 20:1, there is no degradation of C18:1 ethyl ester and the degradation of C18:2 ethyl ester is reduced to $22.6 \%$ (from $3.1 \%$ to $2.4 \%$ ). In this case, the yield would reach 91.6\% (see Table 1).

These results prove the importance of using raw materials with low polyunsaturated compounds to produce biodiesel via the one-step supercritical method. A reduction of linoleic acid ethyl ester from $3.1 \%$ to $2.4 \%$ could be acceptable, but the same percentage reduction in oils with high C18:2 fatty acid content, such as rapeseed or soybean oil, would cause a major loss of material, and the formation of gaseous products or polymers which could affect the final biodiesel properties. ${ }^{21}$ It is worth mentioning that the presence of water can reduce the degradation, ${ }^{44,45}$ but as described before, this could affect the yield of FAEEs in batch production and only could be recommended in a continuous process.

3.2.2. Two-Step Process. The degradation of oleic and linoleic acid ethyl esters is shown in Figures 6 and 7. All the

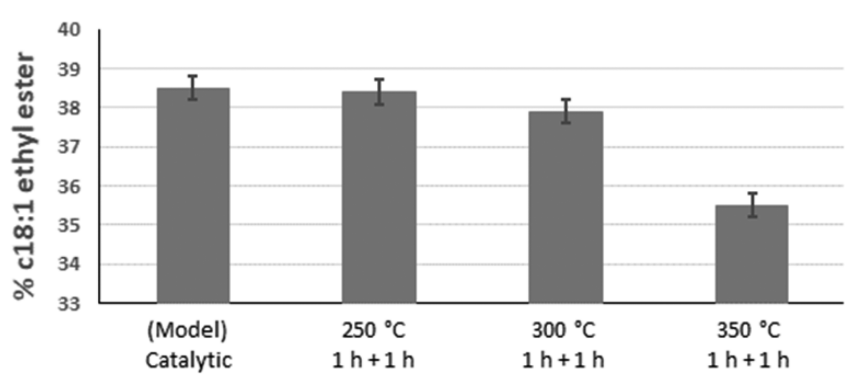

Figure 6. Percentage of oleic acid ethyl ester after two-step process reactions.

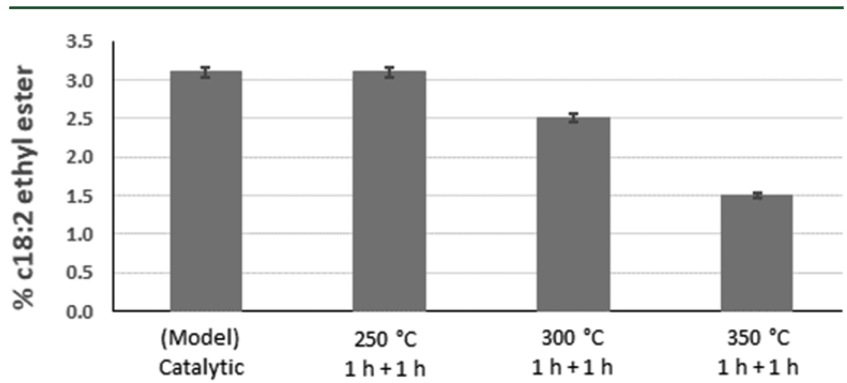

Figure 7. Percentage of linoleic acid ethyl ester after two-step process reactions.

experiments with acceptable yield (more than 90\%) were considered, and to compare with the one-step process reactions, the percentage of ester was measured at the end of the process, consisting of $1 \mathrm{~h}$ of hydrolysis and $1 \mathrm{~h}$ of esterification. The volume ratio water:animal fat was always $2: 1$, and the molar ratio ethanol:FFAs was 7:1 for the second step.

In the worst case $\left(350{ }^{\circ} \mathrm{C}\right)$, degradation is even higher than the one produced during the one-step process. The C18:1 ethyl ester is reduced by $7.8 \%$ (from $38.5 \%$ to $35.5 \%$ ) while the C18:2 ethyl ester is reduced by $51.6 \%$ (from $3.1 \%$ to $1.5 \%$ ). This bigger degradation during the two-step process, when the whole process is at $350{ }^{\circ} \mathrm{C}$ and for $2 \mathrm{~h}$, could be caused by a lower stability of FFAs compared to the triacylglycerides.

Nevertheless, the most important result obtained in Figures 6 and 7 is that, when hydrolysis and esterification reactions are performed at $250{ }^{\circ} \mathrm{C}$, there is no perceptible degradation of neither C18:1 ethyl ester nor C18:2 ethyl ester. The yield of FAEEs would be $90 \%$ (see Figure 3). This result shows a great advantage of the two-step process over the one-step process, especially when dealing with oils with high content of polyunsaturated compounds. Other studies have also reported degradation of polyunsaturated compounds during high pressure and temperature reactions ${ }^{22,46}$ and come to the conclusion that supercritical processes should always be performed at temperatures lower than $300{ }^{\circ} \mathrm{C}$. Moreover, the higher reaction times used in this work for the two-step process compared to the one-step process can be reduced with the use of a continuous process or cosolvents as shown in previous works. ${ }^{47,48}$ 


\section{CONCLUSIONS}

One of the main problems of using waste oils for the production of biodiesel is their high free fatty acids content, which makes the traditional catalytic process more expensive, adding an acid-catalyzed esterification before the transesterification. An alternative method is to use high pressure and temperatures without catalyst, overcoming the problem of acidity. This work has studied the production of biodiesel (FAEEs) from animal fat, using ethanol and two different supercritical methods. The generalized use of ethanol would make biodiesel a complete green energy, contrary to the use of methanol, which currently has a fossil origin. Briefly, the two processes considered have been: (1) The one-step process, where FAEEs are obtained through one single reaction of the animal fat with ethanol; and (2) the two-step process, where, first, a hydrolysis reaction turns the raw animal fat into free fatty acids and, second, free fatty acids react with ethanol to produce FAEEs. On one hand, the two-step process seems especially convenient when the oil used for the production of FAEEs is rich in unsaturated compounds, because an acceptable yield is reached at $250{ }^{\circ} \mathrm{C}$ with no degradation of mono- and polyunsaturated compounds. On the other hand, the one-step process is simpler and can be an interesting alternative for animal fat or oil sources with low polyunsaturated compounds.

\section{ASSOCIATED CONTENT}

\section{S Supporting Information}

The Supporting Information is available free of charge on the ACS Publications website at DOI: 10.1021/acs.energyfuels.7b02991.

Examples of a GPC chromatogram after hydrolysis reaction and after esterification reaction (PDF)

\section{AUTHOR INFORMATION}

\section{Corresponding Author}

*E-mail: laureano.canoira.lopez@upm.es. Tel: (+34) 913366949.

\section{ORCID $\odot$}

Laureano Canoira: 0000-0003-1048-972X

\section{Notes}

The authors declare no competing financial interest.

\section{ACKNOWLEDGMENTS}

We thank Cornelia Sitzwohl and Sigrid Lagarde for their technical help and Argent Energy (UK) Limited for supplying the tallow feedstock.

\section{REFERENCES}

(1) Key World Energy Trends. Excerpt from: World Energy Balances; International Energy Agency: Paris, 2016.

(2) Technology Roadmap: How2Guide for Bioenergy; International Energy Agency: Paris, 2016.

(3) Hedegaard, K.; Thyø, J. K. A.; Wenzel, H. Life Cycle Assessment of Bio-diesel from Animal Fat; Institute for Product Development: Kgs. Lyngby, Denmark, 2007.

(4) Wyatt, V. T.; Hess, M. A.; Dunn, R. O.; Foglia, T. A.; Haas, M. J.; Marmer, W. N. Fuel properties and nitrogen oxide emission levels of biodiesel produced from animal fats. J. Am. Oil Chem. Soc. 2005, 82 (8), 585-591.

(5) Canoira, L.; Rodríguez-Gamero, M.; Querol, E.; Alcántara, R.; Lapuerta, M.; Oliva, F. Biodiesel from low-grade animal fat: production process assessment and biodiesel properties characterization. Ind. Eng. Chem. Res. 2008, 47 (21), 7997-8004.

(6) Bhale, P. V.; Deshpande, N. V.; Thombre, S. B. Improving the low temperature properties of biodiesel fuel. Renewable Energy 2009, 34 (3), 794-800.

(7) Pérez, Á.; Casas, A.; Fernández, C. M.; Ramos, M. J.; Rodríguez, L. Winterization of peanut biodiesel to improve the cold flow properties. Bioresour. Technol. 2010, 101 (19), 7375-7381.

(8) Bhatti, H. N.; Hanif, M. A.; Qasim, M.; Ata-ur-Rehman. Biodiesel production from waste tallow. Fuel 2008, 87 (13-14), 2961-2966.

(9) Dias, J. M.; Alvim-Ferraz, M. C.; Almeida, M. F. Production of biodiesel from acid waste lard. Bioresour. Technol. 2009, 100 (24), 6355-6361.

(10) Lu, J.; Nie, K.; Xie, F.; Wang, F.; Tan, T. Enzymatic synthesis of fatty acid methyl esters from lard with immobilized Candida sp. 99125. Process Biochem. 2007, 42 (9), 1367-1370.

(11) Alptekin, E.; Canakci, M. Optimization of pretreatment reaction for methyl ester production from chicken fat. Fuel 2010, 89 (12), $4035-4039$.

(12) Canakci, M.; Van Gerpen, J. Biodiesel production via acid catalysis. Trans. ASAE 1999, 42 (5), 1203-1210.

(13) Leung, D. Y.; Wu, X.; Leung, M. K. H. A review on biodiesel production using catalyzed transesterification. Appl. Energy 2010, 87 (4), 1083-1095.

(14) Demirbas, A. Biodiesel from waste cooking oil via base-catalytic and supercritical methanol transesterification. Energy Convers. Manage. 2009, 50 (4), 923-927.

(15) Chen, L.; Liu, T.; Zhang, W.; Chen, X.; Wang, J. Biodiesel production from algae oil high in free fatty acids by two-step catalytic conversion. Bioresour. Technol. 2012, 111, 208-214.

(16) Olivares-Carrillo, P.; Quesada-Medina, J. Synthesis of biodiesel from soybean oil using supercritical methanol in a one-step catalystfree process in batch reactor. J. Supercrit. Fluids 2011, 58 (3), 378384.

(17) Gonzalez, S. L.; Sychoski, M. M.; Navarro-Díaz, H. J.; Callejas, N.; Saibene, M.; Vieitez, I.; Jachmanián, I.; da Silva, C.; Hense, H.; Oliveira, J. V. Continuous catalyst-free production of biodiesel through transesterification of soybean fried oil in supercritical methanol and ethanol. Energy Fuels 2013, 27 (9), 5253-5259.

(18) Da Silva, C.; De Castilhos, F.; Oliveira, J. V.; Cardozo Filho, L. Continuous production of soybean biodiesel with compressed ethanol in a microtube reactor. Fuel Process. Technol. 2010, 91 (10), 12741281.

(19) Kusdiana, D.; Saka, S. Two-step preparation for catalyst-free biodiesel fuel production. Appl. Biochem. Biotechnol. 2004, 115 (1-3), $781-791$.

(20) Minami, E.; Saka, S. Kinetics of hydrolysis and methyl esterification for biodiesel production in two-step supercritical methanol process. Fuel 2006, 85 (17), 2479-2483.

(21) Imahara, H.; Minami, E.; Hari, S.; Saka, S. Thermal 2 of biodiesel in supercritical methanol. Fuel 2008, 87 (1), 1-6.

(22) Vieitez, I.; da Silva, C.; Alckmin, I.; de Castilhos, F.; Oliveira, J. V.; Grompone, M. A.; Jachmanián, I. Stability of ethyl esters from soybean oil exposed to high temperatures in supercritical ethanol. $J$. Supercrit. Fluids 2011, 56 (3), 265-270.

(23) He, H.; Wang, T.; Zhu, S. Continuous production of biodiesel fuel from vegetable oil using supercritical methanol process. Fuel 2007, 86 (3), $442-447$.

(24) EN ISO 3675: Crude petroleum and liquid petroleum products. Laboratory determination of density. Hydrometer method; International Organization for Standardization: Geneva, Switzerland, 1998.

(25) EN ISO 3104: Petroleum products. Transparent and opaque liquids. Determination of kinematic viscosity and calculation of dynamic viscosity; International Organization for Standardization: Geneva, Switzerland, 1994.

(26) EN ISO 12937: Petroleum products. Determination of water. Coulometric Karl Fischer titration method; International Organization for Standardization: Geneva, Switzerland, 2000. 
(27) EN 14104: Fat and oil derivatives. Fatty Acid Methyl Esters (FAME). Determination of acid value; British Standards Institute: Herndon, VA, 2003.

(28) DGF-Einheitsmethoden- Abteilung C-Fette C-III 2 (97) Gesamtfettsäuren; Scientific Publishing Company Stuttgart (WVG): Stuttgart, 2005.

(29) EN ISO 20846: Petroleum products. Determination of sulfur content of automotive fuels. Ultraviolet fluorescence method; International Organization for Standardization: Geneva, Switzerland, 2004.

(30) EN 14538: Fat and oil derivates. Fatty Acid Methyl Esters (FAME). Determination of $\mathrm{Ca}, \mathrm{K}, \mathrm{Mg}$ and $\mathrm{Na}$ content by optical emission spectral analysis with inductively coupled plasma (ICP OES); British Standards Institute: Herndon, VA, 2006.

(31) EN 14107: Fat and oil derivates. Fatty Acid Methyl Ester (FAME). Determination of phosphorus content by inductively coupled plasma (ICP) emission spectrometry; British Standards Institute: Herndon, VA, 2003. (32) Darnoko, D.; Cheryan, M.; Perkins, E. G. Analysis of vegetable oil transesterification products by gel permeation chromatography. $J$. Liq. Chromatogr. Relat. Technol. 2000, 23 (15), 2327-2335.

(33) Kucek, K. T.; César-Oliveira, M. A. F.; Wilhelm, H. M.; Ramos, L. P. Ethanolysis of refined soybean oil assisted by sodium and potassium hydroxides. J. Am. Oil Chem. Soc. 2007, 84 (4), 385-392.

(34) EN 14103: Fat and oil derivatives. Fatty Acid Methyl Esters (FAME). Determination of ester and linolenic acid methyl ester contents; British Standards Institute: Herndon, VA, 2011.

(35) Lee, F. M.; Pahl, R. H. Solvent screening study and conceptual extractive distillation process to produce anhydrous ethanol from fermentation broth. Ind. Eng. Chem. Process Des. Dev. 1985, 24 (1), $168-172$.

(36) Kusdiana, D.; Saka, S. Effects of water on biodiesel fuel production by supercritical methanol treatment. Bioresour. Technol. 2004, 91 (3), 289-295.

(37) Silva, C.; Weschenfelder, T. A.; Rovani, S.; Corazza, F. C.; Corazza, M. L.; Dariva, C.; Oliveira, J. V. Continuous production of fatty acid ethyl esters from soybean oil in compressed ethanol. Ind. Eng. Chem. Res. 2007, 46 (16), 5304-5309.

(38) Vieitez, I.; Pardo, M. J.; Da Silva, C.; Bertoldi, C.; De Castilhos, F.; Oliveira, J. V.; Jachmanián, I.; Grompone, M. A. Continuous synthesis of castor oil ethyl esters under supercritical ethanol. J. Supercrit. Fluids 2011, 56 (3), 271-276.

(39) Kusdiana, D.; Saka, S. Kinetics of transesterification in rapeseed oil to biodiesel fuel as treated in supercritical methanol. Fuel 2001, 80 (5), 693-698.

(40) Demirbaş, A. Biodiesel from vegetable oils via transesterification in supercritical methanol. Energy Convers. Manage. 2002, 43 (17), 2349-2356.

(41) Gui, M. M.; Lee, K. T.; Bhatia, S. Supercritical ethanol technology for the production of biodiesel: process optimization studies. J. Supercrit. Fluids 2009, 49 (2), 286-292.

(42) Levine, R. B.; Pinnarat, T.; Savage, P. E. Biodiesel production from wet algal biomass through in situ lipid hydrolysis and supercritical transesterification. Energy Fuels 2010, 24 (9), 5235-5243.

(43) Abdala, A. C. D. A.; dos Santos Garcia, V. A.; Trentini, C. P.; Cardozo Filho, L.; da Silva, E. A.; da Silva, C. Continuous catalyst-free esterification of oleic acid in compressed ethanol. Int. J. Chem. Eng. 2014, 2014, 803783.

(44) Abdala, A. C. D. A.; Colonelli, T. A. D. S.; Trentini, C. P.; Oliveira, J. V.; Cardozo-Filho, L.; Silva, E. A. D.; Silva, C. D. Effect of additives in the reaction medium on noncatalytic ester production from used frying oil with supercritical ethanol. Energy Fuels 2014, 28 (5), 3122-3128.

(45) Silva, C.; Colonelli, T. A. S.; Silva, E. A.; Cabral, V. F.; Oliveira, J. V.; Cardozo-Filho, L. Continuous catalyst-free production of esters from Jatropha curcas L. oil under supercritical ethanol. Braz. J. Chem. Eng. 2014, 31 (3), 727-735.

(46) Imahara, H.; Minami, E.; Hari, S.; Saka, S. Thermal stability of biodiesel in supercritical methanol. Fuel 2008, 87 (1), 1-6.
(47) Mello, B. T. F.; Zempulski, D. A.; Cardozo-Filho, L.; Silva, C. Hydrolysis of Canola Oil Under Subcritical Conditions for Biodiesel Synthesis. Asian J. Chem. 2017, 29 (2), 398.

(48) Ferreira de Mello, B. T.; Gonçalves, J. E.; de Menezes Rodrigues, G.; Cardozo-Filho, L.; da Silva, C. Hydroesterification of crambe oil (Crambe abyssinica H.) under pressurized conditions. Ind. Crops Prod. 2017, 97, 110-119. 